\title{
Comparative Salt Stress Study on Intracellular Ion Concentration in Marine and Salt-adapted Freshwater Strains of Microalgae
}

\author{
Ahmad Farhad TALEBI ${ }^{1,2}$, Meisam TABATABAEI ${ }^{2 *}$,Seyed Kaveh \\ MOHTASHAMI ${ }^{2}$, MasoudTOHIDFAR ${ }^{2}$, Foad MORADI ${ }^{3}$ \\ ${ }^{1}$ Ferdowsi University of Mashhad, College of Agriculture, Biotechnology and Plant Breeding Dept., Mashhad, Iran \\ ${ }^{2}$ Agricultural Biotechnology Research Institute of Iran (ABRII), Biofuel Research Team (BRTeam), Energy Crops Genetic Engineering \\ Group, Microbial Biotechnology and Biosafety Dept., Karaj, Iran; meisam_tab@yahoo.com ("*orresponding author) \\ ${ }^{3}$ Agricultural Biotechnology Research Institute of Iran (ABRII), Molecular Physiology Dept., Karaj, Iran
}

\begin{abstract}
Salinity imposes significant stresses in various living organisms including microalgae. High extracellular concentration of $\mathrm{Na}^{+}$ directly influences ionic balance inside the cell and subsequently the cellular activities. In the present study, the effect of such stress on growth and intracellular ions concentration (IIC) of Dunaliella salina and Chlorella Spp. was investigated. IIC was analyzed using Ion chromatography technique. D. salina showed the highest degree of resistance to increase in salinity as little changes occurred both in IIC and in growth parameters. D. salina could maintain the balance of $\mathrm{K}^{+}$inside the cell and eject the excess $\mathrm{Na}^{+}$even at $\mathrm{NaCl}$ concentrations above $1 \mathrm{M}$. Moreover, D. salina accumulated $\beta$-carotene in order to protect its photosynthetic apparatus. Among Chlorella species, C. vulgaris showed signs of adaptation to high content of salinity, though it is a fresh water species by nature. Moreover, the response shown by $C$. vulgaris to rise in salinity was even stronger than that of $C$. salina, which is presumably a salt-water resistant species. In fact, $C$. vulgaris could maintain intracellular $\mathrm{K}^{+}$better than $C$. salina in response to increasing salinity, and as a result, it could survive at $\mathrm{NaCl}$ concentrations as high as $0.75 \mathrm{M}$. Marine strains such as $D$. salina well cope with the fluctuations in salinity through the existing adaptation mechanisms i.e. maintaining the $\mathrm{K}^{+} / \mathrm{N}^{+}$balance inside the cell, $\mathrm{K}^{+}$accumulation and $\mathrm{Na}^{+}$ejection, accumulation of photosynthetic pigments like $\beta$-carotene.
\end{abstract}

Keywords: Chlorella, Dunaliella, ion chromatography, microalgae, salinity

Abbreviations: Chl a - Chlorophyll a, Chl b - Chlorophyll b; IIC - Intracellular ion concentration

\section{Introduction}

Exceptionally salt tolerant (halotolerant) organisms could enrich our knowledge in knowing basic physiological mechanisms that may lead to enhance salinity tolerance in crops. Algae are inhabitants of biotopes characterized by varying salinities, and as a result they have attracted considerable attention in salt tolerance studies domain. They have served as model organisms for better understanding of salt acclimation in more complex physiological processes of higher plants (Alkayal et al., 2011). Among algal species, the unicellular green algae; Dunaliella salina, due to its remarkable ability to adapt to highly saline conditions, could act as a valuable model for the identification of such mechanisms (Chen and Jiang, 2009). This organism can practically adapt to the entire range of salinities, well above the maximal salinity range for growth of most plant species. The adaptation to extreme salinity involves short-term and long-term responses in Dunaliella sp.; the former include osmotic adjustment by accumulation of large amounts of intracellular glycerol and efficient elimination of $\mathrm{Na}^{+}$by plasma membrane transporters. Rapid alterations in cell volume donated by lacking a rigid cell wall in this genus makes it possible to respond to changes in salt concentration by intracellular ions and glycerol concentration adjustments (Kacka and Donmez, 2008).

On the other hand, Chlorella is a genus of single-cell green microalgae, belonging to the same phylum as $\mathrm{Du}$ naliella sp., Chlorophyta, but is of fresh water habitat. Through photosynthesis, it multiplies rapidly, while requiring only carbon dioxide, water, sunlight, and a small amount of minerals. Algae species can be quit helpful for understanding the mechanisms involved in such resistance since they show adaptation to fluctuations in salinity of their aquatic biotope.

As a matter of fact, increases in external concentrations of inorganic ions impairs the osmotic balance between the cells and their surrounding medium and forces water efflux (exosmosis) from the cells, leading to the loss of turgor pressure (Fricke and Peters, 2002); in this respect, plants, 
310

including species of Chlorophyta, response to high concentrations of salt by assimilation metabolites like those of fructose, sucrose and trehalose, which possess an osmolyte function, or those of charged molecules, such as proline and glycine betaine in order to readjust osmotic equilibrium by preventing water loss (Banu et al., 2009).

Series of studies have been conducted to determine the osmotic responses of such Dunaliella sp. to the changes of salinity (Chen and Jiang, 2009). The results suggest that Dunaliella cells possess efficient mechanisms to eliminate $\mathrm{Na}^{+}$, accumulate $\mathrm{K}^{+}$and to remain intracellular $\mathrm{Ca}^{+2}$ non-exchangeably with the extracellular pool (Pick et al., 1986b). Among these ions, $\mathrm{K}^{+}$is the most contributing to the osmotic balance while $\mathrm{Ca}^{+2}$ play an important role in cell permeability. $\mathrm{Ca}^{+2}$ contributes to osmotic balance maintenance in limited range since it is confined to specific cell compartments like chloroplast matrix (Kirst, 1977). The most known resistant species of this genus is $D$. salina which has developed special adaptation mechanisms to overcome hyper-saline environment; lack of rigid cell wall, accumulation of glycerol in varied concentrations (Kacka and Donmez, 2008), fluctuations in photosynthetic pigments, and structural modifications in chloroplast (Stonynova and Toncheva, 2003). Rapid alterations in cell volume donated by lacking a rigid cell wall makes $D$. salina possible to respond to changes in salinity, by intracellular ions and glycerol concentration adjustments (Kacka and Donmez, 2008).

In an interesting investigation, aerobic decomposition of the unicellular green alga Chlorella salina CU-1 was studied in freshwater and saline cultures. From the physiological point of view, $\mathrm{Ca}^{+2}$ in certain ratios to $\mathrm{Na}^{+}$reversed most of $\mathrm{NaCl}$ stress symptoms in C. salina (Chan, 1985). $\mathrm{Ca}^{+2}$, as second messenger play a significant role in induction of phosphorylation cascades leading to activation of genes responsible for adaptation to high salt resistance and reactive oxygen species (ROS). Application of gypsum increased the chlorophyll and protein contents of $C$. vulgaris in all the concentrations of $\mathrm{NaCl}$ studied. This treatment could alleviate the adverse effects of saline stress (Mathad and Hiremath, 2009).

Having considered the salient role of Dunaliella sp. in studying the physiology of halophilous plants, this study was set to better understand salt responsiveness of the intracellular ion accumulation (IIC) by measuring common cations such as sodium, potassium and calcium using conductivity detectors in an ion chromatography (IC). Moreover, the present study was designed to look for putative evolutionary adaptive changes (high salt stress) by looking into the populations of originally fresh water green algae; Chlorella genus (i.e. C. emersonii, and C. vulgaris) and to determine their IIC while comparing with those of their saline-water relative, $D$. salina.

\section{Materials and methods}

\section{Strain collection and cultivation media}

Four algae species were purchased from the Culture Collection of Algae and Protozoa (CCAP) (Sams Research, Scotland). Those species included three fresh water species of Trebouxiophyceae: C. vulgaris $211 / 11 \mathrm{~B}$, C. emersonii 211/11A, C. salina 211/25, as well as one member of the Chlorophyceae class, D. salina 19/18 which is a salt water inhabitant. All the Chlorella species were cultivated in Moh202, a medium developed in our previous studies (Talebi et al., 2013) and was used for all fresh water strains. Moh202 consisted of $\mathrm{MgSO}_{4} 0.1 \mathrm{~g} / \mathrm{L}, \mathrm{CaCl}_{2} 0.03$ $\mathrm{g} / \mathrm{L}, \mathrm{KNO}_{3} 0.8 \mathrm{~g} / \mathrm{L}, \mathrm{K}_{2} \mathrm{HPO}_{4} 0.15 \mathrm{~g} / \mathrm{L}, \mathrm{KH}_{2} \mathrm{PO}_{4} 0.2 \mathrm{~g} / \mathrm{L}$, Fe-citrate $0.02 \mathrm{~g} / \mathrm{L}$. NaCl concentration for control culture was set up at $0.5 \mathrm{mM}$ in addition to the trace elements (standard Hunter's trace-elements $=1 \mathrm{ml} / \mathrm{L}$ ). The culture medium for $D$. salina also included the same nutrient elements but $\mathrm{NaCl}$ concentration was set at $1,1.5$ and $2 \mathrm{M}$. In this study, sodium bicarbonate was used instead of $\mathrm{CO}_{2}$ injection due to its ease of use.

\section{Growth condition and growth survey}

All strains were cultured under continuous illumination $\left(80 \mu \mathrm{mol}\right.$ photon $\left.\mathrm{m}^{-2} \mathrm{~s}^{-1}\right)$ at $22^{\circ} \mathrm{C}$ in a shaking growth chamber. During the cultivation period, growth kinetic parameters were measured in triplicates for all the strains. Data comparison was then carried out using the ANOVA test. The parameters analyzed included:

1) The cell density determined by measuring the absorbent of $1 \mathrm{ml}$ of cell suspension by a spectrophotometer at $600 \mathrm{~nm}$ wavelength.

2) A step by step course of increasing salinity of culture medium from $0.5 \mathrm{mM}$ (associated with fresh water cultivation) to $0.25,0.5$, and $0.75 \mathrm{M} \mathrm{NaCl}$, was conducted and the adaptive changes of the populations of the abovementioned microalgae strains were measured phenotypically i.e. the changes in chlorophyll content and growth rate and intracellular ion accumulation.

3) Moreover, only for $D$. salina, total chlorophyll and $\beta$-carotene content were measured by spectrophotometery at $412,431,460$ and $480 \mathrm{~nm}$ wavelengths (Eijckelhoff and Dekker, 1997).

Cultures were allowed to grow for $30 \mathrm{~d}$ in order to reach the stationary phase when cells were harvested for further analysis.

\section{Ion chromatography sample preparation}

To determine the intracellular cation content of the cells, $800 \mathrm{ml}$ of algal suspension was centrifuged $30 \mathrm{~d}$ after the cultivation. The pellet was then washed with deionized water and the procedure was repeated. Finally the pellet was lyophilized at $-40^{\circ} \mathrm{C}$ for $48 \mathrm{~h}$ and $0.1 \mathrm{gr}$ dried biomass was combusted in a muffle oven at $520^{\circ} \mathrm{C}$ for $12 \mathrm{~h}$. The colorless ash was dissolved in $10 \mathrm{ml}$ of $0.1 \mathrm{M}$ Hydrochlo- 
ric acid $(\mathrm{HCl})$. Aqueous solutions were then incubated at $80^{\circ} \mathrm{C}$ for $2 \mathrm{~h}$. One $\mathrm{mL}$ of filtered solutions (Wattman filter, No. 3),was diluted in the ratio of 1:10 by deionized water and was implemented for analysis of common intracellular cations.

\section{Results and discussion}

\section{Analysis of algal species using growth parameters}

Growth characteristics of $D$. salina, as a resistant microalgae strain was tested against 3 different species belonging to the Chlorella genius as originally fresh water habitants. As expected, D. salina could reach the highest optical density in the cultivation period (Fig. 1). After three weeks of inoculation of $D$. salina, all cultures with different salinity concentrations reached the stationary growth phase. The lowest cell density was observed at $2 \mathrm{M}$ salinity by $\mathrm{OD}<1$ in day 30 in comparison with OD 2.2 recorded for the medium supplemented with1 M salt (Fig. 1). The dynamics of cell density in Chlorella genus was more various, for example C. emersoni was found so sensitive to different levels of $\mathrm{NaCl}$ in media (Fig. $2 \mathrm{a}$ ) and salinities more than $0.1 \mathrm{M}$ completely inhibited the growth and thus harvesting proper biomass for this species was just applicable from the control media. This species could not resist to such salinity in a prolonged period $(>17 \mathrm{~d})$ and the produced biomass completely vanished. On the other hand, $C$. vulgaris moderately resisted to 0.25 and $0.5 \mathrm{M} \mathrm{NaCl}$ in medium and produced biomass as much as half of that produced in the control medium. At $0.75 \mathrm{M} \mathrm{NaCl}$, the growth of $C$. vulgaris was slightly hindered (Fig. 2 b). As for C. salina, there was a lag phase during the first week after inoculation. However, during the second week of cultivation, a rapid exponential growth started reaching the OD of around 1 by the end of third week. There was no significant difference in terms of growth rate between the control and salt treatments in case of C. salina culture, except for $0.75 \mathrm{M}$ treatment, under which $C$. salina growth was totally inhibited. It seemed that $C$. salina failed to adapt to changes in salinity concentrations of above $0.5 \mathrm{M}$ (Fig. $2 \mathrm{c}$ ).
What is clearly observable from the cell density measurements as seen in Fig. 1 and 2 is the decrease in growth rate with increasing salinity concentrations. $D$. salina showed growth inhibition on day 12 of cultivation at $2 \mathrm{M}$ $\mathrm{NaCl}$ cultures (Fig. 1). Similarly, in another study, D. salina cells were found to show the highest growth rate on day 17 in $1 \mathrm{M} \mathrm{NaCl}$, and on day 13 at $0.5 \mathrm{M} \mathrm{NaCl}$ (Mishra et al., 2008). Chlorella spp. showed approximately a similar trend but at lower salinity levels (Fig. 2a, b and c).

C. salina showed a high degree of resistance to salinity among Chlorella species as revealed a good exponential growth rate at moderate salinity concentrations i.e. $0.5 \mathrm{M}$ $\mathrm{NaCl}$ (Fig. 2c). This could be predicted since C. salina is by nature a saline resistant strain. Nevertheless, this species could not survive at elevated salt concentration of $0.75 \mathrm{M}$ and the growth was inhibited. In contrast, $C$. vulgaris; a sweet water strain, produced promising results in adaptation to salinity. What is clearly seen from the growth pattern of C. vulgaris (Fig. 2b) is that although its exponential growth at $0.75 \mathrm{M} \mathrm{NaCl}$ concentrations was deteriorated but high salinity did not stop its growth. Therefore, it could be concluded that a kind of adaptation had occurred. This kind of data is interesting since C. vulgaris is an important industrial candidate for applications such as biofuel production and bioremediation, and therefore, such capability of adaptation to hyper-saline conditions would be very promising.

C. emersonii showed the least tolerance to salinity (Fig. 2a); this shows physiological incapability of C. emersonii to adapt to hyper saline culture conditions. Setter and Greenway (1983) observed that the growth of C. emersonii was inhibited when $0.2 \mathrm{M} \mathrm{NaCl}$ was present. In the present experiment, C. emersonii showed growth for 17 days at 0.5 $\mathrm{M} \mathrm{NaCl}$ concentration but the growth suddenly dropped afterwards. This was the same case for the other freshwater species in previous studies where a moderate decrease in the rate of cell divisions was reported for Scenedesmus opoliensis at high salinity concentrations (Demetriou et al., 2007). In another salt tolerance analysis in C. sorokiniana, decreased growth rate but at the same time increased pro-

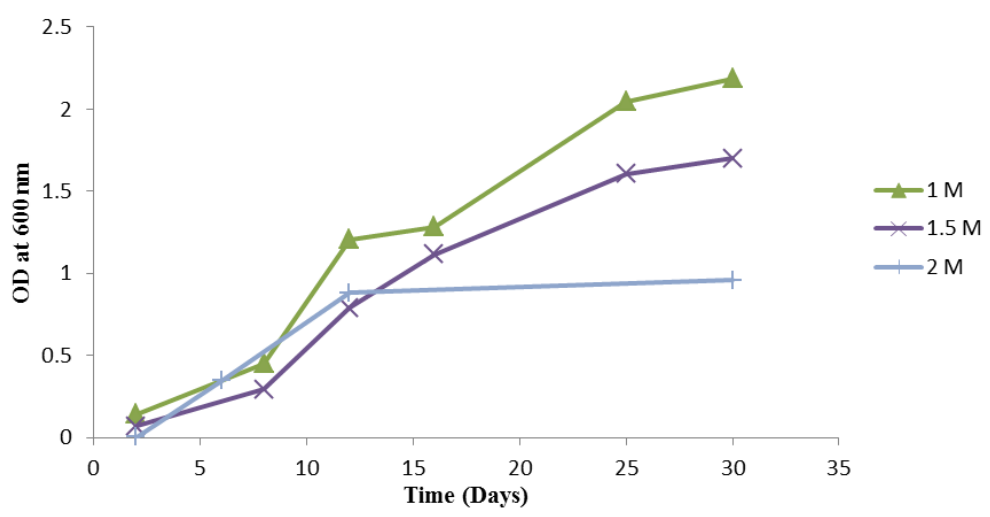

Fig. 1. Variation of cell density in the culture of $D$. salina grown under different salinity concentration 
312

duction of dry weigh was declared (Chimiklis and Karlander, 1973).

In the present study, as shown in Fig. 2 a, b, and c, all fresh-water species were negatively affected by increasing the salt accumulation in media and loss of biomass production were recorded. This trend was in agreement with findings of the previous studies on the impact of increasing salt concentration on biomass production in fresh-water species of $S$. opoliensis and $S$. platensis (Demetriou et al., 2007; Shalaby et al., 2010). When cells are exposed to high salinity, special processes are activated such as, a) restoration of turgor pressure, $b$ ) regulation of the uptake and export of ions through the cell membrane, and c) induction of the accumulation of osmo-protecting solutes and stress proteins. These mechanisms in turn lead to new steady state growth. Beside these mechanisms, there are several other mechanisms needed to ensure successful adaptation to salt tolerance like increasing energy supply through the synthesis of photosynthetic pigments i.e. $\beta$-carotene. This has been well documented in D. salina (Allakhverdiev $e t$ al., 2000).

\section{D. salina pigment production in response to salinity}

The results obtained for pigments production by $D$. salina in response to three different levels of salinity are tabulated in Tab. 2. Chlorophyll a ( $\mathrm{Chl} \mathrm{a)} \mathrm{accumulation}$ showed a slight but significant increase from 3.896 to $6.349 \mu \mathrm{M}$ by increasing $\mathrm{NaCl}$ concentration from 1.5 to 2 $\mathrm{M}$, respectively, indicating cells' strategy for compensating this stress by increasing their photosynthesis activity. Measuring the variations observed in Chl b concentrations in $D$. salina caused by the salinity treatments revealed no logical trend and Chl b concentration only fluctuated around $1 \mu \mathrm{M}$. Same results were previously reported where $3 \mathrm{M}$
$\mathrm{NaCl}$ concentration led to a slight increase in the ratio of $\mathrm{Chl} \mathrm{a/b} \mathrm{(Mishra} \mathrm{et} \mathrm{al.,} \mathrm{2008).} \mathrm{One} \mathrm{possible} \mathrm{reason} \mathrm{to} \mathrm{this}$ matter would be the optimum salinity for the growth of this strain which falls within the range of 1 to $2 \mathrm{M}$. Moreover, these results could also be explained by the fact that small amount of $\mathrm{NaCl}$ creates a slight stress condition compensated by the development of a more extended light harvesting complex (Liu and Shen, 2005); but the salinity stress in higher ranges significantly induced photo-inhibition through stopping the reparation of photo-damaged photosystem II (Allakhverdiev and Murata, 2008). It has been observed that a higher tolerance is achieved by a relatively increased photon flux density. It suggests the role of light in supporting the energy demands of an efficient protective mechanism against physiological changes caused by the hypertonic environment and the toxicity induced by excessive amounts of the sodium ion (Mendoza et al., 1999). In fact, there is a direct relationship between light intensity and intracellular $\mathrm{Cl}^{-}$and $\mathrm{Na}^{+}$concentration (Chimiklis and Karlander, 1973), where higher light intensities and consequently higher photosynthetic pigments such as $\mathrm{Chl}$ a uphold the light-dependent active transport for $\mathrm{Na}^{+}$ exclusion and $\mathrm{K}^{+}$and $\mathrm{Cl}^{-}$accumulation. Ion accumulation and sodium and chloride exclusion from inside the cell is so energy consuming. In a recent study on C. vulgaris, $\mathrm{NaCl}$ concentrations of 0.1 to $0.4 \mathrm{M}$ were tested, and was observed that at 0.1 to $0.2 \mathrm{M} \mathrm{NaCl}$ concentration, the chl content was increased but was reduced at higher concentrations of $\mathrm{NaCl}$; obviously leading to a lower growth rate (Hiremath and Mathad, 2010). The same results were published on C. autotrophica where the higher the salinity in the culture medium, the lower the rate of photo-assimilation (Ahmad and Hellebust, 1984).
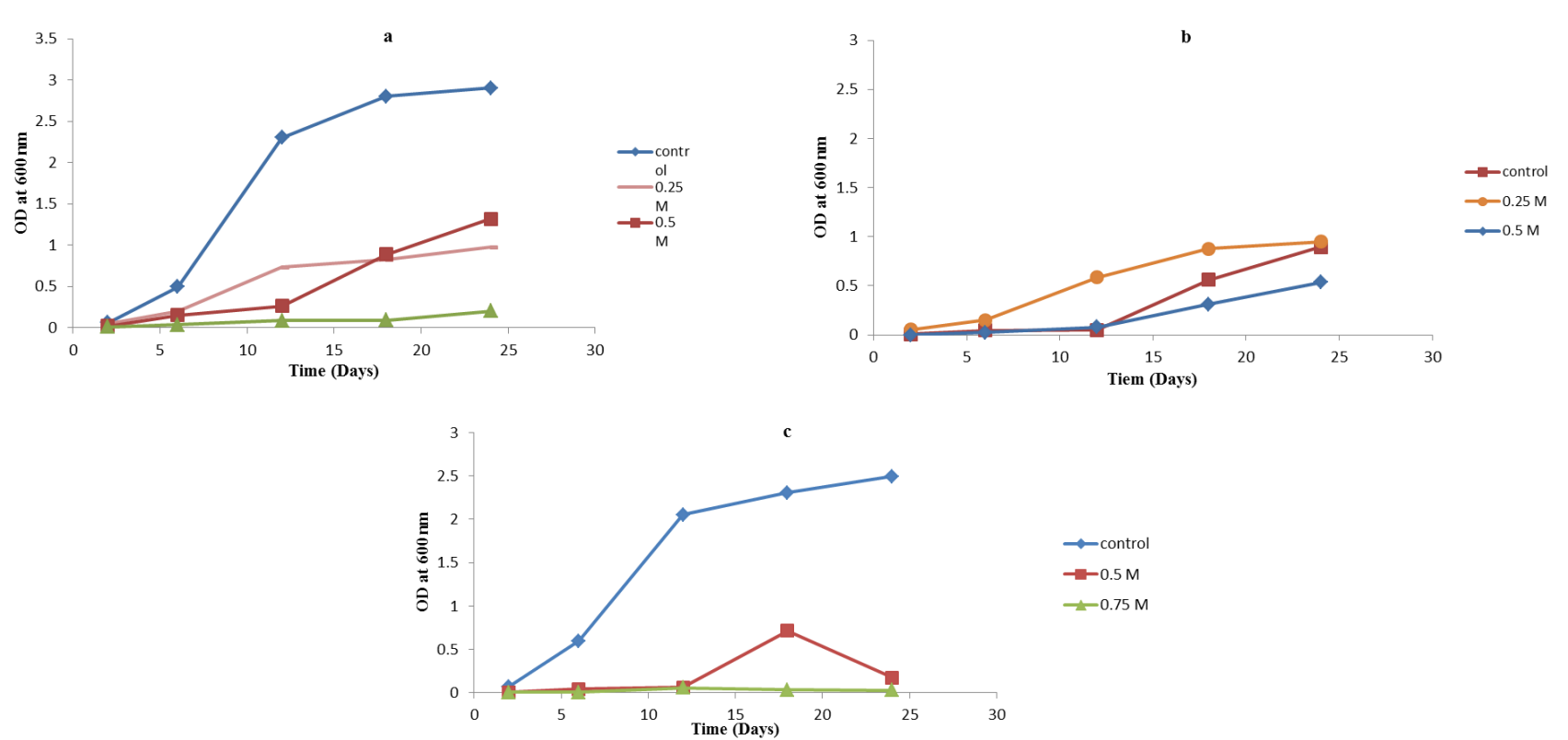

Fig. 2. The influence of different salinity concentrations on the cell density of cultures of a: C. emersonii; b: C. vulgaris; and c: C. salina 
Overall, the presence of excess $\mathrm{NaCl}$ in the environment leads to oxidative stress build-up in all kinds of photosynthetic plants, including the salt tolerant ones. Ion uptake in response to salinity disturbs biopolymers; as a result, some osmo-protective solutes and compounds are induced to accumulate in order to protect bio-compounds from damage (Mc Neil et al., 1999). High ions accumulation as a source of stress has found to stimulate $\beta$-carotene synthesis in $D$. salina. It has been previously suggested that $\beta$-carotene accumulation through ROS protects cells against the deleterious effects of high salinity (Ye et al., 2008 ). In the present study, $\beta$-carotene production by $D$. salina increased continuously as salinity was increased; this trend is clearly shown in Tab. 2. Once salinity was increased from 1 to $1.5 \mathrm{M}, \beta$-carotene accumulation was significantly boosted by $0.54 \mu \mathrm{M}$, and upon increasing in salinity from 1.5 to $2 \mathrm{M}$, even a sharper rise in $\beta$-carotene accumulation was observed by about $0.8 \mu \mathrm{M}$ (Tab. 2). Similar behavior was recorded in cultivation of $S$. platensis in salty media by Shalaby et al. (2010). They reported that cultivation of $S$. platensis under salt stress conditions caused a decrease in dry weight, Chl a content and a slight increase in $\beta$-carotene production and lipid content (Shalaby et al., 2010). In another study, highest cartenoid production in $D$. salina cultures achieved at $3 \mathrm{M} \mathrm{NaCl}$ concentration (Piskal Dipak and Lele, 2005). Furthermore, in a comparative study, $D$. salina was found to produce more cartenoid at $2 \mathrm{M} \mathrm{NaCl}$ than lower concentrations. The increase of $\beta$-carotene production in response to increasing $\mathrm{NaCl}$ concentrations in these organisms supports the idea about the role played by this metabolite in salinity tolerance.

\section{Intracelluar ion concentration}

Ion chromatography is a form of liquid chromatography that uses ion-exchange resins to separate atomic or molecular ions based on their interaction with the resin. In the present study, ion chromatography technique was

Tab. 1. Comparison between IIC in different algae strains grown under salt stress

\begin{tabular}{ccccc}
\hline \multirow{2}{*}{ Strains } & \multicolumn{3}{c}{ Salinity } & \multicolumn{3}{c}{ IIC } \\
\cline { 2 - 5 } & $(\mathrm{M})$ & $\mathrm{Na}$ & $\mathrm{K}$ & $\mathrm{Ca}$ \\
\hline \multirow{2}{*}{$\begin{array}{c}\text { Dunaliella } \\
\text { salina }\end{array}$} & 1.0 & $6.118^{\mathrm{A}^{*}}$ & $0.289^{\mathrm{A}}$ & $1.275^{\mathrm{A}}$ \\
& 1.5 & $6.845^{\mathrm{A}}$ & $0.302^{\mathrm{A}}$ & $0.852^{\mathrm{A}}$ \\
\hline \multirow{3}{*}{ Chlorella } & 0.0 & $10.604^{\mathrm{B}}$ & $0.326^{\mathrm{A}}$ & $0.902^{\mathrm{A}}$ \\
vulgaris & 0.25 & $3.845^{\mathrm{B}}$ & $0.761^{\mathrm{B}}$ & $0.481^{\mathrm{B}}$ \\
& 0.50 & $7.403^{\mathrm{C}}$ & $0.343^{\mathrm{B}}$ & $0.156^{\mathrm{B}}$ \\
\hline \multirow{2}{*}{ Chlorella } & 0.75 & $10.956^{\mathrm{D}}$ & $0.139^{\mathrm{B}}$ & $0.140^{\mathrm{B}}$ \\
salina & 0.0005 & $1.504^{\mathrm{A}}$ & $1.516^{\mathrm{A}}$ & $1.234^{\mathrm{A}}$ \\
& 0.25 & $4.460^{\mathrm{B}}$ & $1.085^{\mathrm{A}}$ & $0.394^{\mathrm{B}}$ \\
\hline
\end{tabular}

The means with the same letter are not significantly different at $p<0.05$, as determined by Tukey's multiple range test for unequal sample size employed to measure intracellular concentrations of cations in algae cells grown under various salt concentrations, the result of which is summarized in Tab. 1. Cells were first rinsed with distilled water so that only the concentrations of cations accumulated inside the cells were measured. Then they were treated with $\mathrm{HCl}$, and the concentration of cations released from dried biomass was measured. This method has been previously used successfully for measurement of intracellular cations i.e. $\mathrm{Na}^{+}, \mathrm{K}^{+}, \mathrm{Ca}^{+2}, \mathrm{Mg}^{+2}$, and $\mathrm{Cl}^{-}$in micro-algae (Chimiklis and Karlander, 1973; Pick et al., 1986 a).

Series of studies have been done to determine the osmotic responses of Dunaliella to the changes of salinity (Chen and Jiang, 2009), however, IIC measurements in unicellular microalgae due to its non-rigid cell have always been controversial. In fact, using a wide range of techniques to determine the Dunaliella cells' volume has caused such variation in measuring intracellular solute concentration (Katz and Avron, 1985). To avoid facing such problem in the present study, instead of measuring cations in the cytoplasm, total cation saluted in $\mathrm{HCl}$ was measured and reported as $\mathrm{mg} / \mathrm{g} \mathrm{DW}$. Based on the data presented in Tab. 1, significant fluctuations were observed in IIC of the algal strains in response to different salinity concentrations.

In case of $D$. salina, increasing the extracellular $\mathrm{NaCl}$ concentration did not lead to a decrease in IIC $\left(\mathrm{Na}^{+}, \mathrm{Ca}^{+2}\right.$ and specially $\mathrm{K}^{+}$). More specifically, intracellular $\mathrm{Na}^{+}$ion increased significantly $(p<0.05)$, by $73 \%$ when $\mathrm{NaCl}$ concentration climbed up from 1 to $2 \mathrm{M}$ (Tab. 1). This shows that $D$. salina cells in comparison with the other strains investigated herein, managed to effectively keep some of the $\mathrm{Na}^{+}$ions out in order to maintain the intracellular balance via utilizing a kind of plasma-membrane $\mathrm{Na}^{+} / \mathrm{H}^{+}$anti-porter system. Moreover, $D$. salina cells keep intracellular $\mathrm{Na}^{+}$ ion concentrations in a tolerable range even in presence of $4 \mathrm{M} \mathrm{NaCl}$ in culture medium (Katz and Avron, 1985). In an experiment on Dunaliella conducted by Pick and coworkers, it was shown that increasing $\mathrm{NaCl}$ concentration from 1 to $4 \mathrm{M}$, also caused the intracellular concentration of $\mathrm{Na}^{+}$to rise significantly (Pick et al., $1986 \mathrm{~b}$ ).

On the contrary, intracellular $\mathrm{Na}^{+}$ion in C. vulgaris and C. salina $\mathrm{Na}^{+}$increased very sharply by 185 and $360 \%$, respectively, when extracellular $\mathrm{Na}^{+}$concentration rose from 0.0005 to $0.5 \mathrm{M}$. This reveals the incapability of

Tab. 2.Pigment accumulation in Dunaliella salina cells in response to different salinity levels

\begin{tabular}{cccc}
\hline \multirow{2}{*}{$\begin{array}{c}\text { Salinity } \\
(\mathrm{M})\end{array}$} & \multicolumn{3}{c}{ Pigments } \\
\cline { 2 - 4 } & Chlorophyll a. & Chlorophyll b. & Carotenoid \\
\hline 1.0 & $4.599^{\mathrm{A}^{\mathrm{A}}}$ & $1.103^{\mathrm{A}}$ & $1.438^{\mathrm{A}}$ \\
1.5 & $3.896^{\mathrm{A}}$ & $0.594^{\mathrm{A}}$ & $1.974^{\mathrm{B}}$ \\
2.0 & $6.349^{\mathrm{B}}$ & $1.209^{\mathrm{A}}$ & $2.764^{\mathrm{C}}$ \\
\hline
\end{tabular}

The means with the same letter are not significantly different at $p<0.05$, as determined by Tukey's multiple range test for unequal sample size 
314

Chlorella species in sufficiently keeping the $\mathrm{Na}^{+}$out of the cells in comparison with $D$. salina. Nevertheless, the Chlorella species tested in this study still managed to survive at the $\mathrm{NaCl}$ concentration of as high as $0.5 \mathrm{M}$. This finding was in agreement with those of a previous study on C. sorokiniana, where acquired resistance to salt concentration of $0.3 \mathrm{M}$ was observed (Chimiklis and Karlander, 1973).

$\mathrm{K}^{+}$intracellular concentration did not change considerably by increasing the salinity in the $D$. salina culture. Similar trend was observed for the other marine strain, $C$. salina, and no relation was found between $\mathrm{K}^{+}$intracellular concentration and extracellular salinity level in these two stains. In contrast, this trend was totally different for $C$. vulgaris. Compared with the control $(0.0005 \mathrm{M} \mathrm{NaCl})$, the concentration of intracellular $\mathrm{K}^{+}$dropped significantly by $54 \%$ in $C$. vulgaris when the culture was exposed to $0.25 \mathrm{M} \mathrm{NaCl}$ (Tab. 1). Such trends were quite expected as Dunliella has become adapted to high salinity levels during the course of its evolution. It has been observed that, an increase in $\mathrm{NaCl}$ concentration led to lowered $\mathrm{K}^{+}$uptake rate in $D$. salina cells but did not affect the final concentration of $\mathrm{K}^{+}$in the cell significantly. This is ascribed to the fact that $D$. salina cells exchange $\mathrm{Na}^{+}$with $\mathrm{K}^{+}$from the intracellular; thus, keep $\mathrm{K}^{+} / \mathrm{Na}^{+}$ratio higher than extracellular environment up to 10 to 1000 folds (Pick et al., 1986a). Also, it has been previously reported that the amount of $\mathrm{K}^{+}$ion in Dunaliella cells is kept constant in order to continue its metabolic activities even by varying salinity levels in the culture medium (Ehrenfeld and Cousin, 1984). Such reports validated the results obtained in this study.

It is worth quoting that $\mathrm{K}^{+}$as an essential ion for most of living organisms contributes to keeping the intracellular $\mathrm{K}^{+} / \mathrm{Na}^{+}$ratio in balance. Such mechanism has been developed during the course of evolution as a defense mechanism against hazardous effects of excess $\mathrm{Na}^{+}$. More specifically, $\mathrm{Na}^{+}$could be exchanged with $\mathrm{K}^{+}$so that excess $\mathrm{Na}^{+}$could be ejected from the cells (Pick et al., 1986 a). This ability to keep intracellular concentration of $\mathrm{K}^{+}$out of fluctuations while exposed to different salinity level is donated to the natural habitants of saline conditions by the mother of nature. Such behavior was clearly observed in D. salian and C. salina strains in the present study.

A trend identical to that recorded for $\mathrm{K}^{+}$, was also observed for $\mathrm{Ca}^{+2}$. D. salina cells revealed to have efficient mechanisms to keep intracellular $\mathrm{Ca}^{+2}$ unchanged; increasing salinity resulted in some statistically non-meaningful fluctuations in the concentration of this ion (Tab. 1). In a study conducted by Issa (1996) it was observed that $\mathrm{Du}$ naliella cells accumulated $\mathrm{Ca}^{+2}$ during the normal growth period, and when salinity was increased from 1.5 to $4 \mathrm{M}$, $\mathrm{Ca}^{+2}$ concentration remained constant despite a sharp increase in intracellular $\mathrm{Na}^{+}$content. Similar results were observed in our experiment as $D$. salina cells accumulated $\mathrm{Ca}^{+2}$ during normal growth at $1 \mathrm{M} \mathrm{NaCl}$ concentration.
Intracellular $\mathrm{Ca}^{+2}$ concentration fluctuations were slightly different in Chlorella species. C. vulgaris and $C$. salina showed significant decrease in intracellular $\mathrm{Ca}^{+2}$ by $49 \%$ and $68 \%$ in response to increases in extracellular $\mathrm{Na}^{+}$ concentration from $0.5 \mathrm{mM}$ to $0.25 \mathrm{M}$, respectively (Tab. 1). Since calcium is an important element for algae, due to its contribution to photosynthesis, thylakoid membrane integrity and glycerol metabolism, therefore, it is vital for algal cell to keep intracellular pool of $\mathrm{Ca}^{+2}$ in balance. In algae, $\mathrm{Ca}^{+2}$ absorption takes place through membrane potential where the driving force is obtained by a proton pump (Pick et al., 1986 a). It was observed that addition of $\mathrm{Ca}^{+2}$ to culture media increased tolerance of algae to salinity and that cells became more resistant to higher salinity levels. This could be explained by of the impact of $\mathrm{Ca}^{+2}$ on lowering intracellular $\mathrm{Na}^{+}$by deteriorating the passive $\mathrm{Na}^{+}$ uptake (Chimiklis and Karlander, 1973). $\mathrm{Ca}^{+2}$ in certain ratios to $\mathrm{Na}^{+}$reverses most of $\mathrm{NaCl}$ stress symptoms in the cell; partly it might be because of the inherent mechanism employed by plants during salt stress, generating second messengers including $\mathrm{Ca}^{+2}$ and reactive oxygen species (ROS) (Ye et al., 2008).

Obviously increase in IIC in response to a rise in extracellular ion concentration indicates permeability of membrane of algal cell. The results obtained in this study show that in comparison with $D$. salina, Chlorella species possess more permeable membranes that respond to change in salinity via accumulation of ions. Such capability enables the cell to prevent plasmolysis. The same capability also exists in marine algae Dunaliella as well (Chimiklis and Karlander, 1973) but the main reason that Dunaliella could cope with highly saline conditions way better than its Chlorella counterparts is that the latter could not resist to the both, toxicity caused by high $\mathrm{Na}^{+}$accumulation as well as the loss of essential cations such as $\mathrm{K}^{+}$and $\mathrm{Ca}^{2+}$.

\section{Conclusions}

Overall, a clear correlation could be found between the potential tolerance of species to salinity fluctuations and IIC changes. The most tolerant algal species; D. salina showed the lowest level of response (IIC fluctuations), to increase in extracellular $\mathrm{Na}^{+}$. More specifically, D. salina could resist extra cellular $\mathrm{Na}^{+}$concentration of as high as $2 \mathrm{M}$ by maintaining the balance of $\mathrm{K}^{+}$inside the cell and protecting photosynthetic apparatus. Interestingly, among the Chlorella species studied, only C. vulgaris showed successful adaptation and increased fitness to high salinity levels and the other two species (C. emersonii and $C$. salina, respectively) deceased.

\section{Acknowlegments}

The authors would like to thank Biofuel Research Team (BRTeam) and Agricultural Biotechnology Research Institute Of Iran (ABRII) for financing this study. 


\section{References}

Ahmad I, Hellebust JA (1984). Osmoregulation in the extremely Euryhaline marine micro-alga Chlorella autotrophica. Plant Physiol 74:1010-1015.

Alkayal F, Albion RL, Tillett RL, Hathwaik LT, Lemos MS, Cushman JC (2011). Expressed sequencetag (EST) profiling in hyper saline shocked Dunaliella salina reveals high expression of protein synthetic apparatus components. Plant Sci 179:437-449.

Allakhverdiev SI, Sakamoto A, Nishiyama Y, Murata N (2000). Inactivation of photosystemI and II in response to osmotics stress in Synechococcus contribution of water channels. Plant Physiol 122:1201-1208.

Allakhverdiev SI, Murata N (2008). Salt stress inhibits photosystems II and I in Cyanobacteria. Photosynth Res 98:529539.

Banu NA, Hoque A, Watanabe-Sugimoto M, Matsuoka K, Nakamura Y (2009). Proline and glycine-betaine induce antioxidant defense gene expression and suppress cell death in cultured tobacco cells under salt stress. J Plant Physiol 166:146-156.

Chan Ky (1985). Aerobic decomposition of Chlorella salina in freshwater and saline conditions. Biol Ocean Microbiol 122:35-44.

Chen H, Jiang JG (2009). Osmotic responses of Dunaliella to the changes of salinity. J Cell Physiol 219:251-258.

Chimiklis PE, Karlander EP (1973). Light and calcium interactions in chlorella inhibited by sodium chloride. Plant Physiol 51:48-56.

Demetriou G, Neonaki C, Navakoudis E, Kotzabasis K (2007). Salt stress impact on the molecular structure and function of the photosynthetic apparatus-the protective role of polyamines. Biochim Biophys Acta 1767:272-280.

Ehrenfeld J, Cousin JL (1984). Ionic regulation of the unicellular green alga Dunaliella tertiolecta: response to hypertonic shock. The J Membr Biol 77:45-55.

Eijckelhoff C, Dekker JP (1997). A routine method to determine the Chlorophyll a, Pheophytin A and Beta-Carotene Contents of isolated Photosystem II reaction center complexes. Photosynt Res 52:69-73.

Fricke W, Peters WS (2002). The biophysics of leaf growth in salt-stressed barley. A study at the cell level. Plant Physiol 129:374-388.

Hiremath S, Mathad P (2010). Impact of salinity on the physiological and biochemical traits of Chlorella vulgaris Beijerinck. J Algal Biomass Utln 1:51-59.

Issa AA (1996). The role of calcium in the stress response of the halotolerant green algae Dunaliella bardawil Ben-Amotz et Avron. Phyton 36:295-302.

Kacka A, Donmez G (2008). Isolation of Dunaliella spp. from a hypersaline lake and their ability to accumulate glycerol. Bioresour Technol 99:8348-8352.
Katz A, Avron M (1985). Determination of intracellular osmotic volume and sodium concentration in Dunaliella. Plant Physiol 78:817-820.

Kirst GO (1977). Ion composition of unicellular marine and fresh-water algae, with special reference to Platymonas subcordijbrmis cultivated in media with different osmotic strengths. Oecologia (Berl.) 28:177-189.

Liu XD, Shen YG (2005). Salt-Induced redox-independent phosphorylation of light harvesting Chlorophyll a/b proteins in Dunaliella salina thylakoid membranes. Biochim Biophys Acta 1706:215-219.

Mathad P, Hiremath Sh (2009). Alleviation of saline stress by gypsum in Chlorella vulgaris Beijerinck. J Algal Biomass Utln 1:43.

Mc Neil SD, Nuccio ML, Hanson AD (1999). Betaines and related osmoprotectants. Targets for metabolic engineeing of stress resistance. Plant Physiol 120:945-949.

Mendoza H, Martel A, Jimenez del Rio M, Garcia Reina G (1999). Oleic acid is the main fatty acid related with carotenogenesis in Dunaliella salina. J Appl Phycology 11:15-19.

Mishra A, Mandoli A, Jha B (2008). Physiological characterization and stress-induced metabolic responses of Dunaliella salina isolated from salt pan. J Ind Microbiol Biotechnol 35:1093-1101.

Pick U, Ben-Amotz A, Karni L, Seebergts ChJ, Avron M (1986 a). Partial characterization of $\mathrm{K}^{+}$and $\mathrm{Ca}^{2+}$ uptake systems in the halotolerant alga Dunaliella salina. Plant Physiol 81:875-881.

Pick U, Karni L, Avron M (1986 b). Determination of ion content and ion fluxes in the halotolerant alga Dunaliella salina. Plant Physiol 81:92-96.

Piskal Dipak S, Lele SS (2005). Cartenoid production from microalga, Dunaliella salina. Ind J Biotechnol 4:476-483.

Setter TL, Greenway H (1983). Changes in the proportion of endogenous osmotic solutes accumulated by Chlorella emersonii in the light and dark. Plant, Cell and Environ 6:227234.

Shalaby EA, Shanab Sanaa MM, Singh V (2010). Salt stress enhancement of antioxidant and antiviral efficiency of Spirulina platensis. J Med Plants Res 4:2622-2632.

Stonynova BE, Toncheva PT (2003). Subcellular adaptation to salinity in Dunaliella salina. Biol Plantarum 47:233-236.

Talebi AF, Mohtashami SK, Tabatabaei M, Tohidfar M, Bagheri A, Zeinalabedini M, Hadavand Mirzaei H, Mirzajanzadeh M, Malekzadeh Shafaroudi S, Bakhtiari Sh (2013). Fatty acids profiling: A selective criterion for screening microalgae strains for biodiesel production. Algal Res 2:258-267.

Ye ZW, Jiang JG, Wu GH (2008). Biosynthesis and regulation of carotenoids in Dunaliella: Progresses and prospects. Biotechnol Adv 26:352-360. 